\title{
Behaviour theory and soft transport policy measures
}

\author{
$\operatorname{AUTHOR}(\mathrm{S})$ : \\ Bamberg, Sebastian; Fujii, Satoshi; Friman, \\ Margareta; Gärling, Tommy
}

CITATION:

Bamberg, Sebastian ...[et al]. Behaviour theory and soft transport policy measures. Transport Policy 2011, 18(1): 228-235

ISSUE DATE:

2011-01

URL:

http://hdl.handle.net/2433/131953

\section{RIGHT:}

(c) 2010 Elsevier Ltd; この論文は出版社版でありません。引用の際には 出版社版をご確認ご利用ください。; This is not the published version. Please cite only the published version. 
Running headline: Behaviour Theory and Soft Transport Policy Measures

\section{Behaviour Theory and Soft Transport Policy Measures}

Sebastian Bamberg

Gießen University, Germany

Satoshi Fujii

Kyoto University, Japan

Margareta Friman

Karlstad University, Sweden

\section{Tommy Gärling}

Karlstad University and University of Gothenburg, Göteborg, Sweden

\section{Acknowledgments}

The work on this paper was financially supported by a grant received from the European Union (Successful Travel Awareness Campaigns and Mobility Management Strategies, contract \#518368) to Sebastian Bamberg, by grant \# 17360244 from the Japanese Ministry of Education under the Grant-in-Aid for Scientific Research (B) to Satoshi Fujii, and by grant \#2004-02974 from the Swedish Governmental Agency for Innovation Systems (VINNOVA) to Margareta Friman. 


\begin{abstract}
The aim is to propose a theoretical grounding of soft transport policy measures to reduce car use. A general conceptual framework is first presented to clarify how hard and soft transport policy measures impact on car-use reduction. Two different behavioural theories that have been used to account for car use and car-use reduction are then integrated in a self-regulation theory that identifies three stages of the process of voluntarily changing car use, setting a car-use reduction goal, forming a plan for achieving the goal, and initiating and executing the plan. A number of techniques are described that facilitate the different stages of the process of car-use reduction.
\end{abstract}

Keywords: Soft transport policy measures, travel behaviour, behavioural theory, intervention techniques 


\section{Introduction}

Private car use is in several respects a future threat to the human environment (Gärling \& Steg, 2007). This has led to the development and implementation of transport policy measures aiming at reducing or changing car use (e.g. Kitamura \& Fujii, 1998; Kitamura et al., 1997). The measures are divided into "hard" and "soft." Hard measures include, for instance, improvements of infrastructure for and management of public transport services, increased costs for car use, and prohibition or rationing of car use. These measures may not alone be effective in achieving caruse reduction (Stopher, 2004), and some are difficult to implement because of public opposition or political infeasibility (Gärling \& Schuitema, 2007; Jones, 2003). Interest has therefore increased in soft measures which use techniques of information dissemination and persuasion to influence car users to voluntarily switch to sustainable travel modes (Gärling \& Fujii, 2009; Jones \& Sloman, 2006; Rose \& Ampt, 2003; Taniguchi et al., 2007; Taylor, 2007; Taylor \& Ampt, 2003). Soft transport policy measures are also referred to as voluntary-change measures (Loukopoulos, 2007), psychological and behavioural strategies (Fujii \& Taniguchi, 2006) or mobility management tools (Cairns et al., 2008). Frequently implemented measures include workplace travel plans (encouraging work commuters to not use the car), school travel plans (encouraging parents to not drive their children to school), personalised travel planning (encouraging reduced car use for all trip purposes), marketing of public transport (mass advertising campaigns), and travel awareness campaigns (increasing awareness of problems resulting from car use) (Cairns et al., 2008).

In the following soft transport policy measures are confined to various forms of personalised travel planning. Available empirical evidence for their effectiveness is first briefly summarized. A lack of theoretical grounding of the measures has been noted (Chatterjee \& Bonsall, 2009; Richter et al., 2010b). The main aim of the present paper is to show that behavioural theories provide such a theoretical grounding. A general conceptual framework is first presented to clarify the impact of hard and soft transport policy measures on car users' switching to sustainable travel modes. It is followed by presentation of two behavioural theories which identify psychological determinants of car use as well as car-use reduction. These theories are then integrated in a self-regulation theory providing the theoretical underpinning of techniques that are components of soft transport policy measures. The paper concludes with a discussion of future research needs.

\section{Evidence for the effectiveness of soft transport policy measures}

Several narrative reviews (Brög et al., 2009; Cairns et al., 2008; Richter et al., 2010a; Taylor, 2007) have concluded that a majority of evaluation studies substantiate that soft transport policy measures are effective. Here we want to highlight that this is likewise the conclusion based on two meta-analyses. Metaanalysis is a technique that provides quantitative estimates of effects (see e.g. Lipsey \& Wilson, 2001). Bamberg and Möser (2007b) demonstrated that other conclusions may be drawn based on the results of meta-analyses than narrative reviews.

In one of the meta-analysis Möser and Bamberg (2008) synthesised the results of 141 studies evaluating the car-use reduction effects of workplace travel plans (44 studies), school travel plans (25 studies), and travel awareness campaigns/marketing of public transport (72 studies). Across all 141 studies a significant standardised mean effect size of 0.15 (Cohen's $h$ ) was found, corresponding to a $11 \%$ decrease of the proportion of trips conducted by car (from $61 \%$ to $54 \%$ ). However, all studies used a quasi-experimental treatment group pre-post test design. This design fails to 
control for several factors that reduce the internal validity of causal inferences (Fujii et al., 2009; Stopher et al., 2009). Furthermore, external validity or generalisability of the results is threatened by the fact that most of the synthesised evaluation results were based on non-representative samples.

In the second meta-analysis Fujii et al. (2009) used data from evaluation studies of 15 Japanese "travel feedback programs". The methodological quality of these studies is higher because they used a pre-post-test comparison or control group design which increases internal validity. A standardised mean effect size of 0.17 (Cohen's $d$ ) was calculated. This corresponds to a decrease in the average number of weekly car trips from 6.9 to 5.7. However, the external validity is limited. The total number of studies was small and most of them were based on small non-representative samples.

Furthermore, at least some of the studies seem to have used non-equivalent treatment and comparison groups, thus making it difficult to rule out alternative explanations for the reported post-test differences.

To summarise, the currently available evaluation results provide empirical evidence for that soft transport policies are effective in influencing car users to reduce car use. However, because of the noted methodological problems (Fujii et al., 2009; Stopher et al., 2009), the question still remains somewhat open of how much of the observed car-use reduction can be causally attributed to the impact of the techniques that are components of soft transport policy measures. Furthermore, in their narrative review, Richter et al. (2010a, 2010b) identified many gaps of knowledge and needs for additional research. One recognized research priority is longitudinal panel studies (but see Fujii and Gärling, 2003, and Matsumura, 2008, who have documented sustainable changes up to 4 years) that examine the time course of changes in travel. Further research is also needed to clarify what factors account for the existence (or nonexistence) of long-term effects. Additional research should illuminate how the simultaneous implementation of hard transport policy measures would increase the effectiveness of soft transport policy measures and vice versa. Of most relevance to the present paper, Richter et al. (2010b) concluded that there exists knowledge gaps and needs for research concerning why soft transport policy measures are effective. Such research should be guided by theories, focussing on the evaluation of techniques such as goal setting, plan formation, and customizing of information. Both the cost-effectiveness of single techniques and, more importantly, their combinations need to be assessed.

\section{A theoretical grounding of soft transport policy measures}

In the last decades the need for theory-driven interventions has been recognized (Bartholomew et al., 2006). When there are no explicit theoretical links between interventions and their intended effects, one cannot ascertain why the interventions did or did not work. An evaluation is therefore of less value for improving the intervention. Likewise, when success or failures cannot be attributed to the techniques employed, it is difficult to transfer evaluation results to other implementations, in other locations or targeting other populations.

In implementations of soft transport policy measures, one finds very little explicit statements about a theoretical rationale (Gärling \& Fujii, 2009). Frequently reference is made to social marketing (Jones \& Sloman, 2006). As Thøgersen (2007) note, social marketing is however a tool for assisting the systematic development and implementation of an intervention. Thus, proponents of soft transport policy measures cannot reasonably claim that the techniques they use for changing car use are based on empirically supported theories. 
In the following we will show that theories developed in psychological research have the potential to provide a theoretical grounding of soft transport policy measures. After first presenting a general conceptual framework, two psychological theories which frequently have been used to account for car use or changes in car use are briefly described. We then present a joint theory that combines elements of these theories and, finally, we extend this joint theory in a way such that it would work as a theoretical grounding of soft transport policy measures.

\subsection{A general conceptual framework}

We start with presenting a general conceptual framework relating decision making, discussed later in more detail, to the objective environment and socio-demographic factors which frequently are evoked to account for disaggregate travel behaviour (e.g. Hanson, 1995). In the conceptual framework (see Figure 1) perception of features of the objective environment (e.g. available travel modes, spatial distribution and quality of shopping and leisure facilities) provides the knowledge base from which people derive their personal set of possible travel options. It is assumed that these options consist of trip chains (see Axhausen \& Gärling, 1992; Gärling et al., 2002) defined as bundles of attributes (i.e. purposes, departure and arrival times, travel times, monetary costs). Besides the objective environment, socio-demographic factors (i.e. family structure, income, employment) and situational factors (i.e. family logistics, time pressure, weather, time of day, weekday) influence perception of possible travel options.

\section{Figure 1}

Hard transport policy measures modify the objective environment. It may lead to changes in travel if car users perceive how the environment is modified (e.g. blocked freeway lanes), deliberately reflect on the consequences it may have for the possible set of travel options (e.g. resulting in increased travel time by car), and judge that these consequences provide sufficient reasons to change current car travel (e.g. public transport provides a faster service). In contrast, the aim of soft transport policy measures is to directly influence decision making by altering car users' perceptions of the objective environment, by altering their judgements of the consequences associated with the use of different travel options, and by motivating and empowering them to switch to alternative travel options.

It should be noted that the conceptual framework stresses the interdependence of hard and soft transport policy measures. With the implementation of hard transport policy measures that change the relative attractiveness of travel options, the possibility increases that soft transport policy measures would be effective in motivating and empowering car users to switch to the these options.

\subsection{Behavioural theories of car use and car-use reduction}

In this section theories and some research results are presented with the aim of providing a more detailed picture of the individual decision making that is a component of the general conceptual framework. In the last decade most psychological research targeting determinants of car use or changes in car use has primarily been guided by two theories (Anable et al., 2006): The Theory of Planned Behaviour (TPB) (Ajzen, 1991) and the norm-activation theory (Schwartz, 1977) which are briefly described in the following. 
Theory of Planned Behaviour (TPB). The theory of reasoned action (TRA) was developed in the 1970s (Ajzen \& Fishbein, 1977; Fishbein \& Ajzen, 1974) and was early adopted by transport researchers (Gärling et al., 1998; Golob et al., 1979; Koppelman \& Lyon, 1981). Yet, it never fully replaced discrete choice models (McFadden, 2001). TRA or its successor the theory of planned behaviour (TPB) (Ajzen, 1991) is not a theory of discrete choice but of how an intention to perform behaviour is formed. It is referred to as an expectancy-value theory (Fishbein \& Ajzen, 1975) since it is based on the assumption that an attitude ${ }^{1}$ towards the behaviour is formed by summing the products of the subjective probabilities of the occurrence of and the positive vs. negative evaluations of all salient expected consequences of the behaviour. This assumption is similar to expected utility theories (Starmer, 2004) that have been proposed to account for choices. According to TPB, if alternative behaviours exist, a choice is made among them based on the relative strengths of the intentions to perform the behaviours. An important difference to discrete choice models (see Ben-Akiva et al., 1999) is that the intentions are also determined by other factors than the attitudes towards the behaviours. The TPB stresses the importance of situational constraints. For example, when forming an intention to use car or bus, people do not only take into account their attitudes toward these two travel modes but they also judge the difficulty of using them. This is referred to as perceived behavioural control (PBC). Social norm is a third factor influencing behavioural intention. In TPB social norm is conceptualised as perceived social pressure, that is expectations of the degree to which significant reference persons will approve performance of the behaviour (e.g. the use of a specific travel mode).

Norm-Activation Theory. Originally the norm-activation theory (Schwartz, 1977) aimed at explaining pro-social behaviours. It has later been developed into valuebelief-norm theory (Stern, 2000) to specifically account for pro-environmental values, attitudes and behaviour. The norm-activation theory may fare better than TPB in explaining car-use reduction. Whereas car use predominantly depends on evaluations of positive and negative consequences for the car user (Garvill, 1999), car-use reduction appears to depend more strongly on pro-social motives. This is consistent with findings that personal norm is an important determinant of car-use reduction (e.g. Nordlund \& Garvill, 2003). A personal norm is defined as the felt obligation to bring own behaviour in line with personally important internalised self-standards (e.g. Biel \& Thøgersen, 2007). The formation and activation of personal norms results from an interplay of cognitive, emotional and social factors. Problem awareness and perceived responsibility are cognitive preconditions for its development (Schwartz, 1977).

The perception that one is responsible for a behaviour causing harm to other people frequently triggers feelings of guilt (e.g. Weiner, 1995), which is a pro-social emotion in that it results in a felt obligation to compensate for the caused damage (Baumeister, 1998). Besides feelings of guilt, social norms also contribute to the development of personal norms. Social norms inform people about what behavioural standards their social reference group views as appropriate in a particular context. Personal and social norms coincide when people have internalised such social expectations.

A joint theory. The existence of two empirically supported but contrasting theories for explaining car use and car-use reduction is unsatisfying. Bamberg et al. (2007) and Bamberg and Möser (2007a) therefore proposed to augment TPB by adding 
personal norm from norm-activation theory as another determinant of intention. Furthermore, in the joint theory social norm has a different role than in TPB. In line with research on informational social influence (e.g. Moscovici, 1985), it is assumed that people follow social norms less because they expect social sanctions, as assumed in TPB, but because social norms inform them about what behaviour is normal. Thus, social norms do not only provide information whether a behaviour is morally right or wrong but also whether it is performed by a majority of others.

\section{Figure 2}

Bamberg et al. (2007) conducted two studies in which they successfully applied the joint theory to explain choices of public transport services for daily travel. Furthermore, Bamberg and Möser (2007a) tested the model with meta-analytically synthesised information from 46 studies published since 1995 in peer-reviewed journals. These studies reported correlations between the constructs posited in the joint theory and measures of different pro-environmental behaviours obtained from 57 independent samples. The correlation matrices were input to a meta-analytical structural equation model (MASEM, see Becker, 2000; Viswesvaran \& Ones, 1995). Whereas meta-analysis synthesise quantitative research findings (in this case correlation coefficients) across different studies and contexts, structural equation modelling (SEM) assesses the degree to which a theory-based model (based on the joint theory) fits the empirical pattern of the pooled correlations. Figure 2 shows standardised path coefficients and explained variances. As can be seen, the results support the hypothesis that behavioural intention mediates the effects on behaviour of the other constructs. Intention explains on average $27 \%$ of the variance in behaviour. The hypothesis is also supported that PBC, attitude and personal norm have independent effects on intention. Together they explain on average $52 \%$ of the variance in intention. As hypothesised, feelings of guilt, social norm, responsibility and problem awareness all have significant effects on personal norm. Together these four variables explain on average $58 \%$ of the variance in personal norm. The results also showed that, besides its direct as well as indirect (through feelings of guilt) effects on personal norm, social norm has a direct effect on PBC and attitude. There is furthermore a direct path from feelings of guilt to attitude. The results finally support the hypothesized role of problem awareness since it has a direct effect on responsibility, feelings of guilt, social norm and personal norm.

\section{Table 1}

Gardner and Abraham (2008) reported the results of a meta-analysis synthesising the results of 23 studies of psychological determinants of actual car-use reduction. The right part of Table 1 presents the pooled correlations between car-use reduction and the constructs of the joint theory. As can be seen, the pooled correlations reported for car use are similar to those reported by Bamberg and Möser (2007a) (left part of the table) for different pro-environmental behaviours. Thus, it is suggested that the joint theory may be generalized to account for car-use reduction.

A self-regulation theory of travel change. For the development of soft transport policy measures, a theory is needed of the process of car users' voluntarily changes of their current car use. To this end Bamberg (2010) proposed a self-regulation theory that integrates elements of TPB, the norm-activation theory and the joint 
theory. Self-regulation refers to that the theory applies concepts from control theory (Carver \& Scheier, 1998; Gärling et al., 2002; Loukopoulos et al., 2007).

The self-regulation theory implies transitions through different stages as displayed in Figure 3.The end of the first stage is marked by the setting of a car-use reduction goal and behavioural intention to achieve the set goal (note that also other goals may be set, such as cutting expenses, increasing public transport use). Setting of such a goal may reflect the felt obligation (personal norm) to bring current travel more in line with important self-relevant standards, activated by feelings of guilt due to the perception that current travel has negative collective consequences in conjunction with perceived own responsibility for these negative consequences. Social norms are viewed as another possible determinant of the felt obligation to reduce car use. Setting of the goal of car-use reduction also depends on perceived goal feasibility, that is perception of possible alternative travel options. Since a car-use reduction goal is not specific enough to directly guide a change in travel, a behavioural plan or intention (e.g. using the bus or the bike instead of the car) needs to be formed to reach the goal. Formation of a behavioural intention or plan to choose another travel option as the means of achieving the car-use reduction goal marks the end of the second stage. Initiation and feedback-controlled execution of the new travel option marks the end of the third stage.

\section{Figure 3}

Bamberg (2010) reported a correlational test of the self-regulation theory. A sample of 1,358 adults was asked which of several statements expressed their personal car-use reduction goal for the next month. The statement "My goal is to decrease my car use" was chosen by $20 \%$ of the sample, "I would like to decrease my car use, but I am unable to do so at the present time" by $18 \%$, "My goal is to stay at the same level of car use" by $22 \%$, "My goal is to increase my car use" by $2 \%$, and "I have no goal to change my car use" by $39 \%$. Figure 4 shows that, as theoretically expected, a strong association is observed between awareness of the negative collective consequences of current car use and the perceived responsibility to contribute to the reduction of these negative consequences $\left(\beta=0.79 ; R^{2}=0.63\right)$. Feelings of guilt mediate the relationship between perceived responsibility and personal norm. Perceived responsibility affects feelings of guilt $\left(\beta=0.70 ; R^{2}=0.49\right)$ which in turn affect personal norm $(\beta=.21)$. The results also provide weak evidence for that perceived responsibility affects social norm (expectations of approval be important reference persons) $\left(\beta=0.23 ; R^{2}=0.05\right)$. Furthermore, social norm affect personal $(\beta=0.57)$. Together with feelings of guilt $(\beta=0.21)$, social norm explains $41 \%$ of the variance in personal norm. As hypothesized, personal norm is directly $(\beta$ $=.18)$ as well as indirectly associated with the intention to achieve the car-use reduction goal through its significant association with goal feasibility $(\beta=.26)$, emotions anticipated from goal progress $(\beta=.34)$ and failure $(\beta=.15)$. Besides, goal intention is associated with goal feasibility $(\beta=.59)$ and emotions anticipated from goal progress $(\beta=.37)$. Together, personal norm, goal feasibility and emotions anticipated from goal progress explain $65 \%$ of the variance in goal intention.

Confronted with the question which behavioural strategy they would use to achieve their car-use reduction goal, participants choose most frequently the two options "Using public transport more frequently for everyday trips" (29\%) and "Walk more frequently for everyday trips shorter than $3 \mathrm{~km}$ " $(26 \%)$. The selection of the specific behavioural intention or plan for reaching the intended caruse reduction goal is affected by goal intention $(\beta=.51)$ and behavioural control $(\beta$ 
$=.63)$, and to a smaller degree by personal norm $(\beta=.12)$ and attitude $(\beta=.10)$. Together, these variables explain $68 \%$ of the variance in behavioural intention. The results also show that behavioural planning is significantly associated with behavioural intention $(\beta=.52)$ and perceived behavioural control $(\beta=.18)$. Together the variables explain $44 \%$ of the variance in behavioural planning.

\section{Figure 4}

\section{Theory-based techniques}

Based on the self-regulation theory, more cost-effective soft transport policy measures may be developed. Particularly important is the conceptualization of voluntary car-use reduction as a transition through different stages, forming a goal intention to reduce car use, forming a behavioural intention to do this, and choosing the alternative travel option that reduces car use.

Currently, one single measure is usually used for all car users (Richter et al., 2010a). If car-use reduction is a transition through different stages, more flexibility would be needed, allowing matching the measure employed to the stage of the car user. If targeting car users in an early stage, the measure would likely be more effective if targeting problem awareness and perceived responsibility. Making social norms salient would also be important in this stage. For car users who already have formed a car-use reduction intention, providing information about the availability as well as evaluations of different alternative travel options would be more effective. Persons who already have formed an intention to use a specific alternative travel option would benefit most from support of its implementation.

The self-regulation theory also provides a "blueprint" for theory-based techniques as components of soft transport policy measures. Table 2 summarizes how the process stages posited by the theory may be connected to specific techniques that are likely to enhance the outcome of the stage. A variety of techniques exist that aim at making social norms salient, for instance mass media role-modelling (e.g., McAlister, 1995, see also Goldstein \& Cialdini, 2007; Schulz, 1998). Scenario-based risk information (e.g. Hendrickx et al., 1989) and consciousness raising (e.g. Prochaska et al., 2002) are examples of techniques that increases problem awareness and responsibility. Locke and Latham (2002) have demonstrated that stimulating the setting of feasible but challenging goals leads to better performance than does setting easy goals. However, the positive effect of difficult goals depends on that people accept the challenge and have sufficient experience, possess self-efficacy and obtain adequate feedback (e.g. McCalley \& Midden, 2002). There are also a number of techniques that aim at increasing the perceived behavioural control as well as positive attitudes towards alternative options (e.g. Ajzen \& Manstead, 2007). Linking members to new networks by mentor programs, buddy systems, and self-help groups (e.g. Heaney \& Israel, 2002) are examples. Examples of techniques that would facilitate goal achievement include planning or practicing when, where, and how to initiate a new behaviour (e.g. Gärling \& Fujii, 2002; Gollwitzer, 1999; Gollwitzer \& Sheeran, 2006) as well as training of coping skills like identifying risk situations, practicing solutions, and coping with lapses (e.g. Marlatt \& Gordon, 1985). Immediate customized feedback is important for maintaining the new behaviour (e.g. Carver \& Scheier, 1998).

Table 2 


\section{Future research directions}

Two types of future lines of research are particularly needed for the further development of cost-effective soft transport policy measures. One line of research should concentrate on the theory-based development and experimental tests of techniques. The focus of this research should be based on the insights of behavioural science research addressed in this paper to improve the theory of the causal mechanisms underlying car use as well as its voluntary change. If supported by solid empirical evidence, in a second step the identified causal mechanisms should be systematically connected with techniques potentially able to activate these mechanisms. In a third step a series of small-scale experiments should be conducted to test whether the newly developed techniques are indeed able to activate the causal mechanisms and whether their activation results in behavioural change (for an example of such a research program, see Taniguchi \& Fujii, 2006; Taniguchi et al., 2007). A critical feature of such experiments is the random assignment of participants to experimental and control groups (Fujii et al., 2009). Because the focus of this research is on causality, high internal validity is essential whereas external validity - the generalisability of the results - is less important. For this reason studies aiming at testing the causal effects of new theory-based techniques may use convenience samples. Ideally, as was illustrated in Table 2, this type of research would result in sets of empirically supported causal mechanisms and techniques that activate these mechanisms.

A second type of research should concentrate on the development of large-scale evaluations of prototypes of soft transport policy measures under field conditions. In practice most transport policy measures consist of packages of different empiricallysupported techniques. However, the development of such packages should also be based on theory-driven assumptions about the causal role of each element included in the package. Besides the evaluation of the procedures used for producing and delivering the intervention to the target group (process evaluations), the aim of such large-scale intervention studies is the valid estimation of the behavioural effects of these measure under field conditions (outcome evaluations). For this purpose both high internal and external validity is essential. Thus, to guarantee a high internal validity of the evaluation results, true experimental research designs should be used. Fuji et al. (2009) provide an overview of how to apply such research designs within the context of evaluations of soft transport policy measures. To guarantee high external validity of the results, large-scale evaluations are required based on data from representative population-based samples. As soon as a body of adequate highquality evaluation studies is available, meta-analytic techniques (e.g. Lipsey \& Wilson, 2001) should be used to calculate reliable and precise estimates of the effects. Furthermore, if the synthesis of the available evaluation results indicate a strong variability of the reported effects, meta-analyses provide statistical tools for analysing the potential sources of this variability, that is the possible impact of different population characteristics, differences in techniques, or differences in location. A precondition for this is that the evaluation reports contain enough detailed information about these factors. 


\section{References}

Ajzen, I., and Fishbein, M. (1977). Attitude-behavior relations: A theoretical analysis and review of empirical research. Psychological Bulletin, 84, 888-918.

Ajzen, I. (1991). The theory of planned behavior. Organizational Behavior and Human Decision Processes, 50, 179-211.

Ajzen, I., and Manstead, A. S. R. (2007). Changing health-related behaviors: An approach based on the theory of planned behavior. In K. van den Bos, M. Hewstone, J. de Wit, H. Schut and M. Stroebe (Eds.), The scope of social psychology: Theory and applications (pp. 43-63). New York: Psychology Press.

Anable, J., Lane, B., and Kelay, T. (2006). A review of public attitudes to climate change and transport: summary report. (Research report) London: Department for Transport. Retrieved May 20, 2008, from http://www.dft.gov.uk/pdf/pgr/sustainable/climatechange/areviewofpublicatti tudestocl5731.

Axhausen, K., and Gärling, T. (1992). Activity-based approaches to travel analysis: Conceptual frameworks, models, and research problems. Transport Reviews, 12, 323-341.

Bamberg, S. (2010). Why and how do people voluntarily change environmentally harmful behaviors? A self-regulation approach. Manuscript submitted for publication.

Bamberg, S., and Möser, G. (2007a). Twenty years after Hines, Hungerford, and Tomera: A new meta-analysis of psycho-social determinants of pro-environmental behaviour. Journal of Environmental Psychology, 27, 14-25.

Bamberg, S., and Möser, G. (2007b). Why are work travel plans effective? Comparing conclusions from narrative and meta-analytical research synthesis. Transportation, 34, 647-666.

Bamberg, S., Hunecke, M., and Blöhbaum. (2007). Social context, morality and the use of public transportation: Results from two field studies. Journal of Environmental Psychology, 27, 190-203.

Bartholomew, L. K., Parcel, G. S., Kok, G., and Gottlieb, N. H. (2006). Planning health promotion programs: An intervention mapping approach. San Francisco, CA: Jossey-Bass.

Baumeister, R. F. (1998). The self. In D. T. Gilbert, S. T. Fiske, and G. Lindzey (Eds.), The handbook of social psychology (pp. 680-740). Boston: MacGraw-Hill.

Becker, B. J. (2000). Multivariate meta-analysis. In H. E. A. Tinsley and D. Brown (Eds.), Handbook of applied multivariate statistics and mathematical modelling (pp. 499-525). San Diego: Academic Press.

Ben-Akiva, M., McFadden, D., Gärling, T., Gopinath, D., Bolduc, D., Borsch-Supan, D., Delquie, P., Larichev, O., Morikawa, T., Polydoropoulou, A., and Rao, V. (1999). Extended framework for modeling choice behavior. Marketing Letters, 10, 187-203.

Biel, A., and Thøgersen, J. (2007). Activation of social norms in social dilemmas: A review of the evidence and reflections on the implications for environmental behaviour. Journal of Economic Psychology, 28, 93-112.

Brög, W., Erl, E., Ker, I., Ryle, J., \& Wall, R. (2009). Evaluation of voluntary travel behaviour change: Experiences from three continents. Transport Policy, 16, 281292.

Cairns, S., Sloman, L., Newson, C., Anable, J., Kirkbride, A., and Goodwin, P. (2008). Smarter choices: Assessing the potential to achieve traffic reduction using "soft measures". Transport Reviews, 28, 593-618. 
Carver, C. S., and Scheier, M. F. (1998). On the self-regulation of behavior. New York: Cambridge University Press.

Chatterjee, K., and Bonsall, P. (2009). Special issue on evaluation of programmes promoting voluntary change in travel behaviour. Transport Policy, 16, 279-280.

Fishbein, M., and Ajzen, I. (1974). Attitudes towards objects as predictors of single and multiple behavior criteria. Psychological Review, 81, 59-74.

Fishbein, M., and Ajzen, I. (1975). Belief, attitude, intention, and behavior: An introduction to theory and research. Reading, MA: Addison-Wesley.

Fujii, S., and Taniguchi, A. (2006). Determinants of the effectiveness of travel feedback programs - a review of communicative mobility management measures for changing travel behavior in Japan. Transport Policy, 13, 339-348.

Fujii, S., Bamberg, S., Friman, M., and Gärling, T. (2009) Are effects of travel feedback programs correctly assessed? Transportmetrika, 5, 43-57.

Gardner, B., and Abraham, C. (2008). Psychological correlates of car use: A metaanalysis. Transportation Research F, 11, 300-311.

Gärling, T., Eek, D., Loukopoulos, P., Fujii, S., Johansson-Stenman, O., Kitamura, R., Pendyala, R., and Vilhelmson, B. (2002). A conceptual analysis of the impact of travel demand management on private car use. Transport Policy, 9, 59-70.

Gärling, T., and Fujii, S. (2002). Structural equation modeling of determinants of implementation intentions. Scandinavian Journal of Psychology, 43, 1-8.

Gärling, T., and Fujii, S. (2009). Travel behavior modification: Theories, methods, and programs. In R. Kitamura, T. Yoshii and T. Yamamoto (Eds.), The expanding sphere of travel behaviour research (pp. 97-128). Bingley, UK: Emerald.

Gärling, T., Gillholm, R., \& Gärling, A. (1998). Reintroducing attitude theory in travel behavior research: The validity of an interactive interview procedure to predict car use. Transportation, 25, 147-167.

Gärling, T., and Schuitema, G. (2007). Travel demand management targeting reduced private car use: Effectiveness, public acceptability and political feasibility. Journal of Social Issues, 63, 139-153.

Gärling, T., and Steg, L. (Eds.) (2007). Threats from car traffic to the quality of urban life: Problems, causes, and solutions. Amsterdam: Elsevier.

Garvill, J. (1999). Choice of transport mode: Factors influencing drivers' willingness to redice personal car use and support car regulations. In M. Foddy, M. Smithson, S. Schneider and M. Hogg (Eds.), Resolving social dilemmas: Dynamic, structural, and intergroup aspects (pp. 263-279). Philadelphia. PA: Psychology Press.

Goldstein, N. J., and Cialdini, R. B. (2007). Using social norms as a lever of social influence. In A. R. Pratkanis (Ed.). The science of social influence (pp. 167-192). New York: Psychology Press.

Gollwitzer, P.M. (1999). Implementation intentions: Strong effects of simple plans. American Psychologist, 54, 493-503.

Gollwitzer, P. M., and Sheeran, P. (2006). Implementation intentions and goal achievement: A meta-analysis of effects and processes. Advances in Experimental Social Psychology, 38, 69-119.

Golob, T. F., Horowitz, A. D., and Wachs, M. (1979). Attitude-behavior relationships in travel demand modelling. In D. A. Hensher \& P. R. Stopher (Eds.), Behavioral travel demand modelling (pp. 739-757). London: Croom Helm.

Hanson, S. (Ed.) (1995). The geography of urban transportation. Amsterdam: Elsevier.

Heaney, C. A., and Israel, B. A. (2002). Social networks and social support. In K. Glanz, F. M. Lewis and B. K. Rimer (Eds.), Health behavior and health 
education: Theory, research and practice (pp.185-209). San Francisco, CA: Jossey-Bass.

Hendrickx, L., Vlek, C., and Oppewal, H. (1989). Relative importance of scenario information and frequency information in the judgement of risk. Acta Psychologica, 72, 463.

Jones, P. (2003). Acceptability of road user charging: Meeting the challenge. In J. Schade and B. Schlag (Eds.), Acceptability of transport pricing strategies (pp. 2762). Amsterdam: Elsevier.

Jones, P., and Sloman, L. (2006). Encouraging behavioral change through marketing and management: What can be achieved? In K. W. Axhausen (Eds.), Moving through nets: The physical and social dimensions of travel (pp. 189-218). Oxford: Elsevier.

Kitamura, R., \& Fujii, S. (1998). Two computational process models of activitytravel choice. In T. Gärling, T. Laitila \& K. Westin (Eds.), Theoretical foundations of travel choice modeling (pp. 251 - 279). Amsterdam: Elsevier.

Kitamura, R., Fujii, S., and Pas, E. I. (1997) Time use data for travel demand analysis: Toward the next generation of transportation planning methodologies. Transport Policy, 4, 225-235.

Koppelman, F., and Lyon, P. K. (1981). Attitudinal analysis of work/school travel. Transportation Science, 15, 233-254.

Lipsey, M. W., and Wilson, D. (2001). Practical meta-analysis. Thousand Oaks, CA: Sage.

Locke, E. A., and Latham, G. P. (2002). Building a practically useful theory of goal setting and task motivation: A 35-year odyssey. American Psychologist, 57, $705-$ 717.

Loukopoulos, P. (2007). A classification of travel demand management measures. In T. Gärling and L. Steg (Eds.), Threats from car traffic to the quality of urban life: Problems, causes, and solutions (pp. 275-292). Amsterdam: Elsevier.

Loukopoulos, P., Gärling, T., Jakobsson, C., and Fujii, S. (2007). A costminimization principle of adaptation of private car use in response to road pricing schemes. In C. Jensen-Butler, M. Larsen, B. Madsen, O. A. Nielsen and B. Sloth, B. (Eds.), Road pricing, the economy, and the environment (pp. 331-349). Oxford: Elsevier.

Marlatt, G. A., \& Gordon, J. R. (1985). Relapse prevention: Maintenance strategies in the treatment of addictive behaviors. New York: Guilford Press.

Matsumura, N. (2008). Evaluation of the effect of attitude and travel behavior modification by one-shot TFP for incomer and residents, Journal of Infrastructure Planning and Management, 64, pp.77-85.

McAlister, A. (1995). Behavioral journalism: Beyond the marketing model for health communication. Journal of Health Promotion, 9, 417-420.

McCalley, L. T., and Midden, C. J. H. (2002). Energy conservation through productintegrated feedback: The roles of goal-setting and social orientation. Journal of Economic Psychology, 23, 589-603.

McFadden, D. (2001). Disaggregate behavioral travel demand's RUM side - A 30 years retrospective. In D. A. Hensher (Eds.), Travel behavior research (pp. 17-63). Amsterdam: Elsevier.

Moscovici, S. (1985). Social influence and conformity. In G. Lindsey and E. Aronson (Eds.). Handbook of social psychology (Vol. 2, 3rd ed., pp. 347-412). New York: Random House. 
Möser, G., and Bamberg, S. (2008). The effectiveness of soft transport policy measures: A critical assessment and meta-analysis of empirical evidence. Journal of Environmental Psychology, 28, 10-26.

Nordlund, A. M., and Garvill, J. (2003). Effects of values, problem awareness, and personal norm on willingness to reduce personal car use. Journal of Environmental Psychology, 23, 339-347.

Prochaska, J. O., Redding, C. A., and Evers, K. E. (2002). The transtheoretical model and stages of change. In K. Glanz, C. E. Lewis and B. K. Rimer (Eds.), Health behavior and health education: Theory, research, and practice (pp. 99-120). San Francisco: Jossey-Bass.

Richter, J., Friman, M., and Gärling, T. (2010a). Review of evaluations of soft transport policy measures. Transportation: Theory and Application, 2, 5-18.

Richter, J., Friman, M., and Gärling, T. (2010b). Soft transport policy measures: Gaps of knowledge and research needs. Manuscript submitted for publication.

Rose, G., and Ampt, E. S. (2003). Travel behaviour change through individual engagement. In D. Hensher and K. Button (Eds.), Handbook of transport and the environment (pp. 739-755). Amsterdam: Elsevier.

Schulz, P. W. (1998). Changing behavior with normative feedback interventions: A field Experiment on curbside recycling. Basic and Applied Social Psychology, 21, 25-36.

Schwartz, S. H. (1977). Normative influence on altruism. In L. Berkowitz (Ed.), Advances in experimental social psychology (Vol. 10, pp. 221-279). New York: Academic Press.

Starmer, C. (2004). Developments in nonexpected-utility theory: The hunt for a descriptive theory of choice under risk. In C. F. Camerer, G. Loewenstein \& M. Rabin (Eds.), Advances in behavioral economics (pp. 105-147). Princeton, NJ: Princeton University Press.

Stern, P. C. (2000). Toward a coherent theory of environmentally significant behavior. Journal of Social Issues, 56, 407-424.

Stopher, P. R. (2004). Reducing road congestion: A reality check. Transport Policy, 11, 117-131.

Stopher, P. R., Clifford, E., Swann, N., and Zhang, Y. (2009). Evaluating of voluntary travel behaviour change: Suggested guide lines and case studies. Transport Policy, 16, 315-324.

Taniguchi, A., and Fujii, S. (2007). Promoting public transport using marketing techniques in mobility management and verifying their quantitative effects. Transportation, 34, 37-49.

Taniguchi, A., Suzuki, H., and Fujii, S. (2007). Mobility management in Japan: Its development and meta-analysis of travel feedback programs. Transport Research Record, 2021, 100-109.

Taylor, M. (2007). Voluntary travel behavior change programs in Australia: The carrot rather than the stick in travel demand management. International Journal of Sustainable Transportation, 1, 173-192.

Taylor, M., and Ampt, E. S. (2003). Travelling smarter down under: Policies for voluntary travel behaviour change in Australia. Transport Policy, 10, 165-177.

Thøgersen, J. (2007). Social marketing of alternative transportation modes. In T. Gärling and L. Steg (Eds.), Threats from car traffic to the quality of urban life: Problems, causes, and solutions (pp. 367-381). Amsterdam: Elsevier.

Viswesvaran, C., and Ones, D. C. (1995). Theory testing: Combining psychometric meta-analysis and structural equation modelling. Personnel Psychology, 48, 865885. 
Weiner, B. (1995). Judgments of responsibility: A foundation for a theory of social conduct. New York: Guilford Press. 


\section{Footnote}

${ }^{1}$ Attitude is similar to preference but refers in general to a more enduring disposition of choosing a behaviour. 
Table 1

Pooled correlations (r) between hypothesized determinants and pro-environmental behaviours and car-use reduction, respectively.

\begin{tabular}{lcccccccc}
\hline & \multicolumn{3}{c}{ Pro-environmental behaviours } & \multicolumn{3}{c}{ Car-use reduction } \\
\hline Determinant & $\mathbf{n}$ & $\mathbf{k}$ & $\mathbf{R}$ & $\mathbf{9 5 \%} \mathbf{C I}$ & $\mathbf{n}$ & $\mathbf{k}$ & $\mathbf{r}$ & $\mathbf{9 5 \%} \mathbf{C I}$ \\
\hline Problem awareness & 8,276 & 18 & .22 & {$[.11, .27]$} & 799 & 3 & -.24 & {$[-.33,-.15]$} \\
Perceived responsibility & 1,866 & 6 & .25 & {$[.13, .34]$} & --- & --- & --- & --- \\
Social norm & 7,325 & 18 & .31 & {$[.21, .41]$} & 993 & 2 & .36 & {$[.36, .36]$} \\
Feelings of guilt & 3,203 & 5 & .31 & {$[.21, .38]$} & --- & --- & --- & --- \\
Perceived behavioural control & 8,029 & 18 & .30 & {$[.18, .40]$} & 324 & 2 & .31 & {$[-.05, .65]$} \\
Attitude & 6,751 & 17 & .54 & {$[.26, .56]$} & 569 & 4 & .27 & {$[-.15, .70]$} \\
Personal norm & 6,840 & 11 & .58 & {$[.12, .61]$} & 563 & 2 & -.41 & {$[-.70,-.11]$} \\
Behavioural intention & 5,654 & 15 & .52 & {$[.42, .61]$} & 2,517 & 4 & .53 & {$[.35, .72]$}
\end{tabular}

Note. $\mathrm{k}=$ number of pooled studies; $\mathrm{n}=$ pooled sample size; $\mathrm{CI}=$ confidence interval. 
Table 2. Examples of theory-based techniques.

\begin{tabular}{|l|l|l|}
\hline Process stage & Target of technique & Technique \\
\hline Goal intention & Social norm & Mass media role-modelling \\
& Personal norm & Scenario-based risk information \\
Problem awareness & Consciousness raising
\end{tabular}




\section{Figure captions}

Fig. 1. A general conceptual framework

Fig. 2. Results of path analysis of meta-analytically pooled correlations. (Single-headed arrows represent causal paths, double-headed arrows represent correlations; standardized path coefficients and explained variance are shown). (Adapted from Bamberg and Mösel, 2007.)

Fig. 3. The self-regulation theory's hypothesized stages of the process of behavioural change and their determinants.

Fig. 4. An estimated structural model based on the self-regulation theory of voluntary change of car use. (Standardised path coefficients and explained variances are shown). 


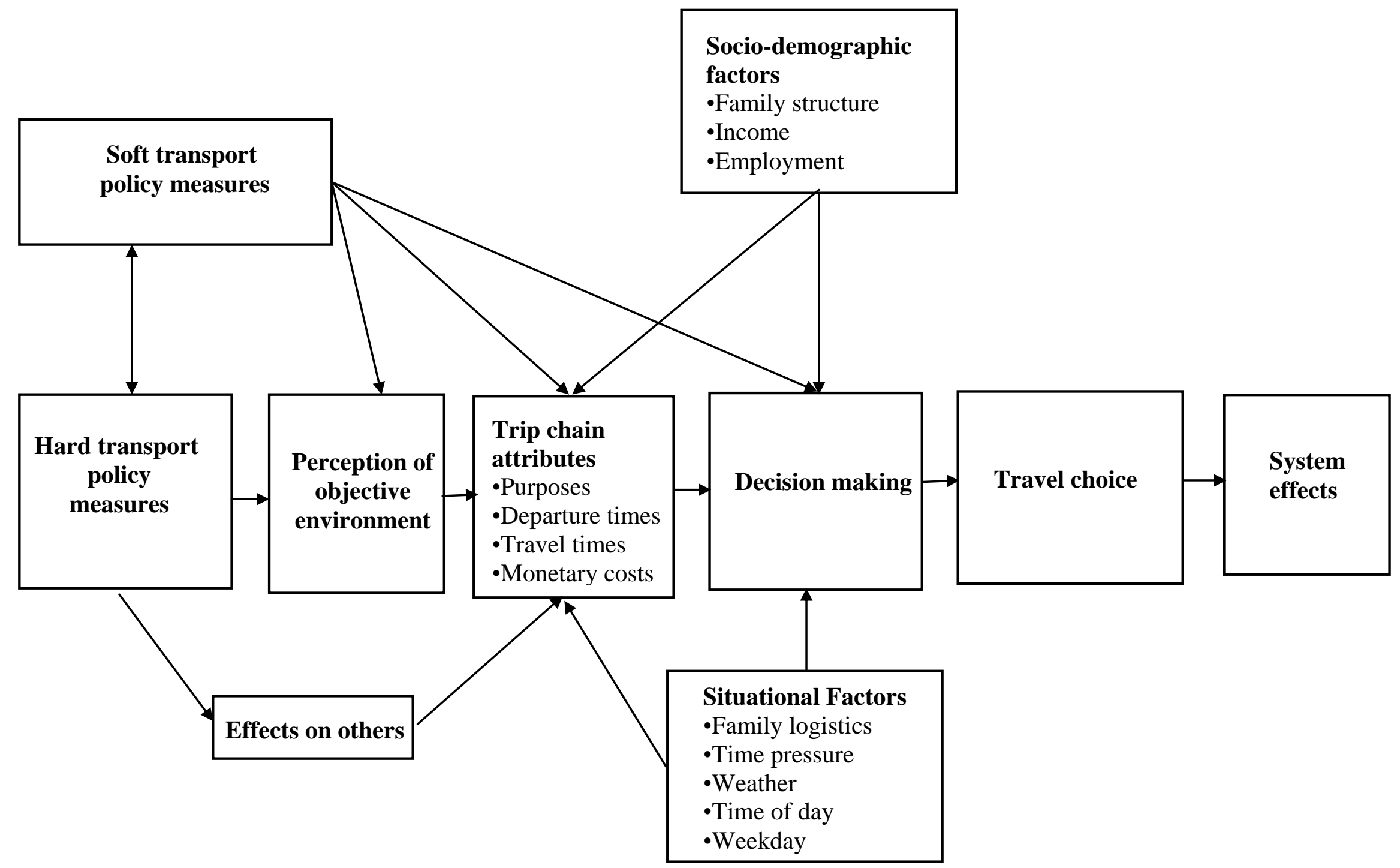

Fig. 1. A general conceptual framework 


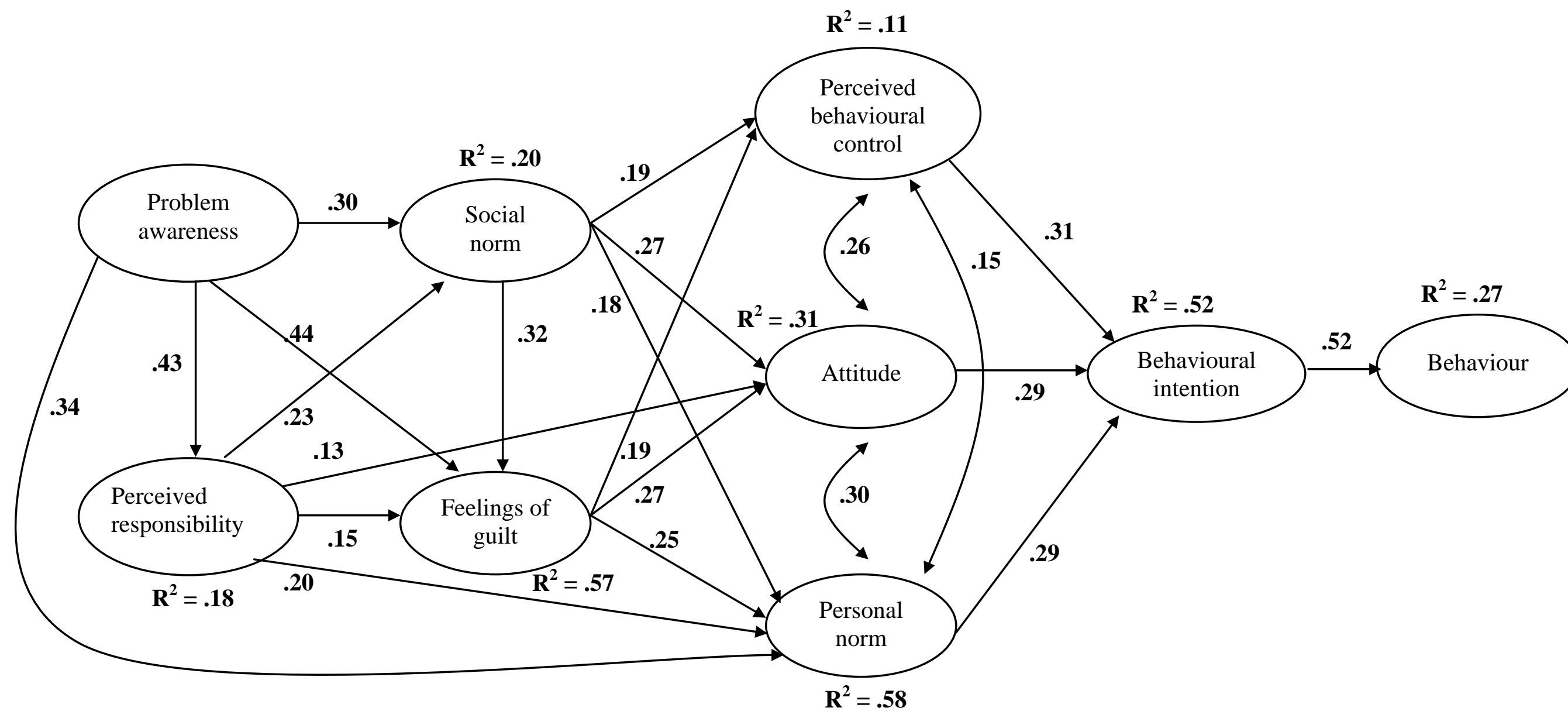

Fig. 2. Results of path analysis of meta-analytically pooled correlations. (Single-headed arrows represent causal paths, doubleheaded arrows represent correlations). (Adapted from Bamberg and Mösel, 2007.) 


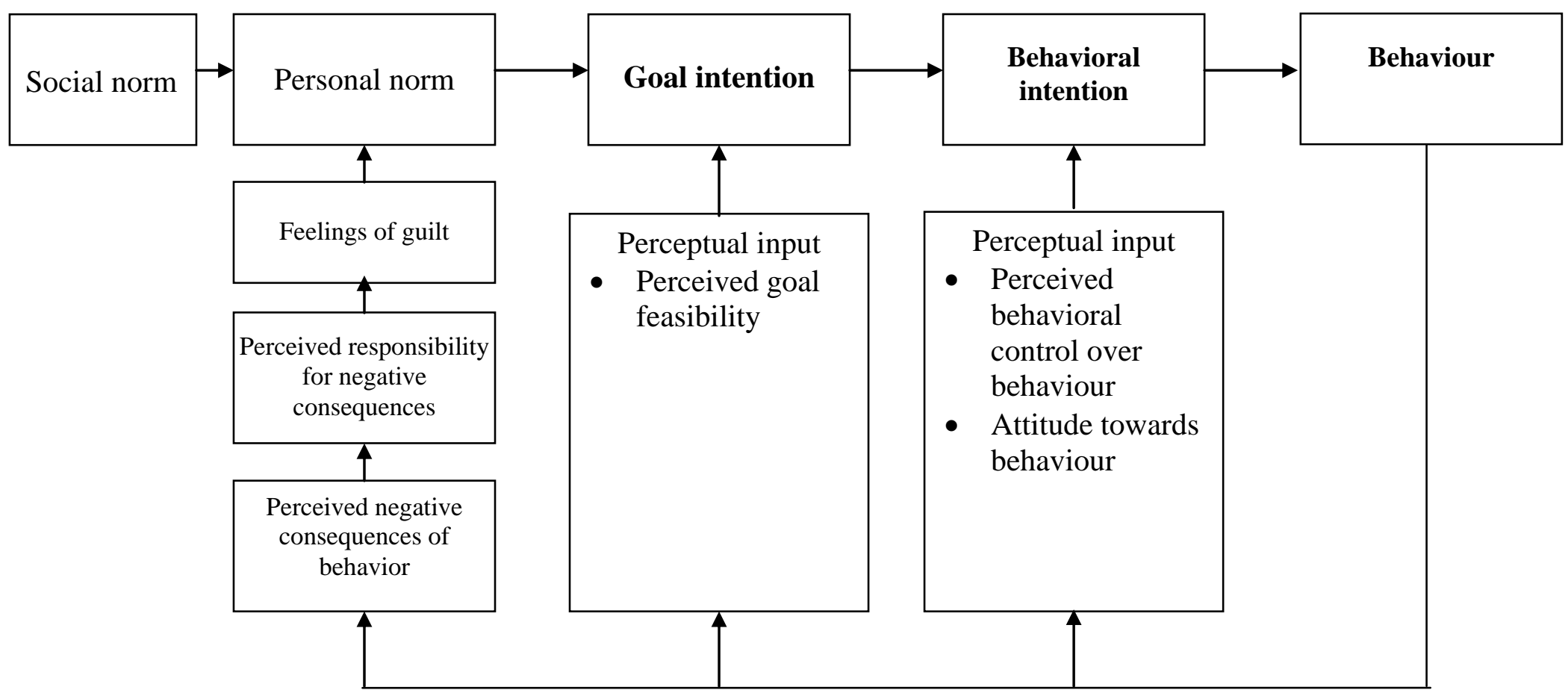

Fig. 3. The self-regulation theory's hypothesized stages of the process of behavioural change and their determinants. 


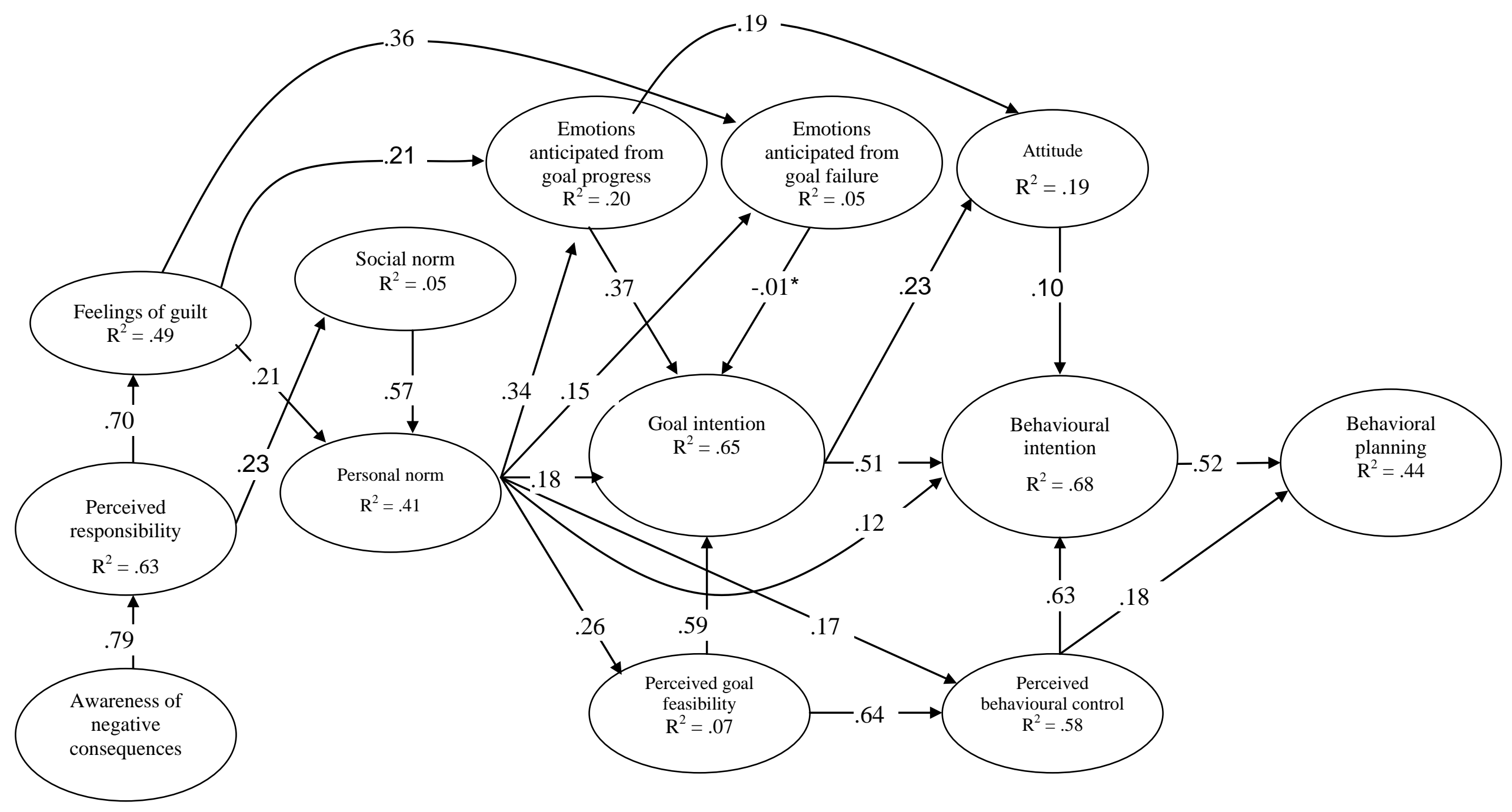

Fig. 4. An estimated structural model based on the self-regulation theory of voluntary change of car use. (Standardised path coefficients and explained variances are shown). 